\title{
First generation anti-CD19 chimeric antigen receptor-modified T cells for management of $B$ cell malignances: initial analysis of an ongoing Phase I clinical trial
}

\author{
Manon Evans ${ }^{1 *}$, Ryan Guest ${ }^{2}$, Dominic Rothwell ${ }^{3}$, Debbie Burt ${ }^{3}$, Natalia Kirillova ${ }^{2}$, Jennifer Haughton ${ }^{1}$, Shien Chow ${ }^{1}$ \\ , Fiona Thistlethwaite', David Gilham ${ }^{4}$, Robert Hawkins ${ }^{1}$
}

From Society for Immunotherapy of Cancer 29th Annual Meeting

National Harbor, MD, USA. 6-9 November 2014

\section{Introduction}

Management of advanced B cell malignancies refractory to standard chemotherapy is challenging with sub-optimal results. Recent clinical reports of durable, objective responses from adoptive transfer of anti-CD19 chimeric antigen receptor (CAR) $\mathrm{T}$ cells have accentuated the potential of this therapy.

Here we report the preliminary results of an on-going Phase I clinical trial at our Institution.

\section{Methods}

This is a single centre, open label, dose escalation, Phase I study of adoptive transfer of autologous $\mathrm{T}$ cells expressing a CD19-specific first generation CAR (aCD19z) with pre-conditioning chemotherapy and intravenous interleukin-2 (IL2), in patients with pre-treated CD19-positive malignancy.

We report data on 2 cohorts: Cohort 1 (4 patients) received $1 \times 10^{9}$ aCD19z T-cells and Cohort 2 (planned 4 patients) $1 \times 10^{10 .}$ Both cohorts received 100,000 u/kg of IL2.

\section{Results}

To date, 6 patients have successfully completed treatment. All patients tolerated treatment well, and experienced anticipated transient grade1-2 toxicities attributable to pre-conditioning chemotherapy and IL2. 5 patients

'Department of Medical Oncology, Christie NHS Foundation Trust, Manchester, United Kingdom

Full list of author information is available at the end of the article developed short lived but significant Grade 4 neutropenia and thrombocytopenia.

4 of 5 patients evaluable to date achieved at least stable disease as best response at 6 weeks post aCD19z $\mathrm{T}$ cell infusion, with 1 patient maintaining response at $400+$ days. 1 patient achieved a very good partial response with a $65 \%$ reduction in disease burden. 2 patients died of disease progression ( 1 of Central Nervous $(\mathrm{CN})$ progression only, not present at baseline); 2 patients died of viral infection over 400 days post infusion; 1 patient with disease control maintained. No patients died of treatment-related complications.

Quantitative polymerase chain reaction (qPCR) analysis of peripheral blood samples detected $\mathrm{aCD} 19 \mathrm{z}$ T cells in both cohorts. Levels peaked at days 4-7 post aCD19z T cell infusion (cohort 1 peak $30 \%$ of total cells, cohort 2 (results available to date) peak 25\%) before falling to lower levels. All patients revealed persisting low frequency levels $(<1 \%)$ at week $6 ; 1$ patient at up to 50 weeks. 1 patient received a further course of low dose IL2 at week 6 resulting in a transient increase in $\mathrm{zCD} 19 \mathrm{z} \mathrm{T}$ cell levels.

All patients demonstrated a significant reduction in peripheral CD19+ T cell numbers post aCD19z T cell infusion, with most substantial results seen in cohort 2 where suppression was seen lasting into week 8 (prior to $\mathrm{CN}$ progression).

\section{Discussion}

Our data contributes to the encouraging growing body of evidence on antiCD19-specific CAR T cells, suggesting significant clinical responses and sustained persistence. Updated results and immune data will be presented. 


\section{Registration Details}

www.clinicaltrials.gov NCT01493453

\section{Consent}

Written informed consent was obtained from the patient for publication of this abstract and any accompanying images. A copy of the written consent is available for review by the Editor of this journal.

\section{Authors' details}

'Department of Medical Oncology, Christie NHS Foundation Trust, Manchester, United Kingdom. ${ }^{2}$ Cellular Therapeutics Limited, Manchester, United Kingdom. ${ }^{3}$ Clinical Immune and Molecular Monitoring Laboratory, Clinical and Experimental Pharmacology Group, Cancer Research UK Manchester Institute, Manchester, United Kingdom. ${ }^{4}$ Clinical and Experimental Immunotherapy Group, Institute of Cancer Sciences, Manchester Academic Healthcare Science Centre, Manchester, United Kingdom.

Published: 6 November 2014

doi:10.1186/2051-1426-2-S3-P12

Cite this article as: Evans et al.: First generation anti-CD19 chimeric antigen receptor-modified $T$ cells for management of $B$ cell

malignances: initial analysis of an ongoing Phase I clinical trial. Journal for ImmunoTherapy of Cancer 2014 2(Suppl 3):P12.

Submit your next manuscript to BioMed Central and take full advantage of:

- Convenient online submission

- Thorough peer review

- No space constraints or color figure charges

- Immediate publication on acceptance

- Inclusion in PubMed, CAS, Scopus and Google Scholar

- Research which is freely available for redistribution 